Portland State University

PDXScholar

$5-24-2018$

\title{
Stress Compulsion: the Creation and Curation of an Art Show
}

Shannen Muhl

Portland State University

Follow this and additional works at: https://pdxscholar.library.pdx.edu/honorstheses Let us know how access to this document benefits you.

\section{Recommended Citation}

Muhl, Shannen, "Stress Compulsion: the Creation and Curation of an Art Show" (2018). University Honors Theses. Paper 623.

https://doi.org/10.15760/honors.634

This Thesis is brought to you for free and open access. It has been accepted for inclusion in University Honors Theses by an authorized administrator of PDXScholar. Please contact us if we can make this document more accessible: pdxscholar@pdx.edu. 


\section{Stress Compulsion:}

\section{The creation and curation of an art show}

By: Shannen Muhl 


\section{Acknowledgments:}

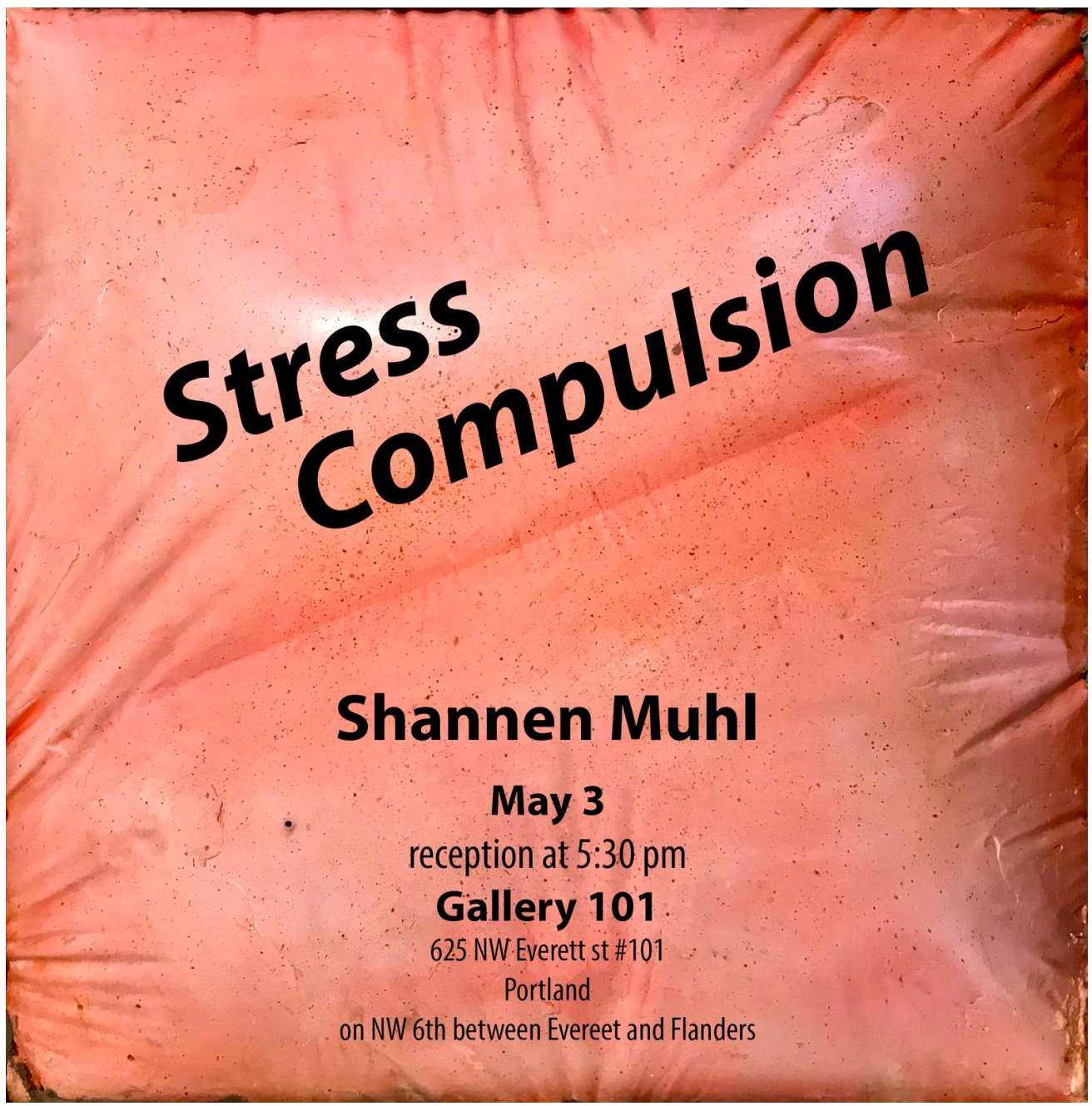

For my brother Sean, the one who convinced me to devote my life to art

A special thanks to those who've brought me into the world, those who have guided me in this world, and those who travel with me in this world.

To my Honors advisor Mark Smith. Thank you for your patience and wisdom through this entire process. 


\section{What it is That I Did}

"Art evokes the mystery without which the world would not exist."

-Rene Magritte-

I am an artist, and as an artist what I do is create art. As an interdisciplinary artist I have the means and capability to use the many tools and disciplines I have studied throughout the years to create. I am able to alter the physical environment, which in the artist world is called form.

Art is a means of communicating an idea that otherwise lacks the literary means of expression. It is a way of allowing the viewer to grasp the intangible by altering their outer environment with stimulus which can then alter their inner environment. This alteration gives the viewer the ability to temporarily be in the mind of the artist, and experience the unexplainable. This is providing the viewer with the content of the work.

"I'm attempting to create a conversation about the mannerisms and anxieties that are caused from living in a cityscape. We cram ourselves into smaller and smaller spaces, and expose ourselves to a variety of chaoses to live in this environment. I have a love hate relationship with this, and I strive to keep it constant." This conversation is some of the context of my work, which helps guide the viewer to having a fuller understanding of its intended meaning.

Once all the work is created I curated an art show in an established art gallery named Gallery 101 during an event known as First Thursday. This is a monthly opening in downtown Portland when most art galleries showcase their newest artists and exhibit their work. 


\section{The Three Corners of Art}

"Creativity is intelligence having fun."

\section{-Albert Einstein-}

Art has three components to observe and to create its whole. Like a triangle with its three corners the three components of art, when used in balance, can create a strong piece from which the observer can experience. These three components are not reserved strictly to only two or three dimensional art like paintings and sculptures, but all forms, such as time based, temporary, audio, etc. These components are form, content, and context. The job of the artist is to manipulate the physical form, apply context, which gives the viewer content. As long as there is somewhat of a balance the art is whole.

\section{Form}

"The elements of art are components or parts of a work of art that can be isolated and defined. They are the building blocks used to create a work of art."(Paul, para 1)

- The purely physical aesthetics of the piece

- The only component the artist is able to control

- The "building blocks" of art

- Physical aspects such as

$\circ$ Line

- Shape

- Texture

$\circ$ Dimensions

- Duration 

- Color
- Medium
- Sound
○ Style
- Technique

\section{Content}

"By reducing the work of art to its content and then interpreting that, one tames the work of art. Interpretation makes art manageable, conformable." (Sontag, p.5)

- The essence of art

- What the viewer receives from experiencing art

- What is "behind the piece"

- Completely subjective

- What the viewer...
$\circ$ Feels
- Sees
- Imagines
- Evokes
- Remembers
- Experiences
- Personalizes
- Internalizes
- Relates

- The artist attempts to manipulate and guides the content 


\section{Context}

"Whether economic, philosophical, social or cultural, the context in which an artwork is created and the complicity of the artist within that context is intrinsic to its meaning."(Pledger, para 5)

- The artist's intent

- The historic placement

- The artist cannot manipulate or control this, just simply inform the viewer

- Social, political, financial, personal, etc. occurrences within the time of the piece or artist

Once these components are understood it's simply a matter experimenting with different balances of form and context to create the content for the viewer. Say that I had created a piece with lots of form, I wouldn't have to necessarily rely on a large amount of context to provide valuable content for the viewer. On the other hand say that the focus was on the amount of context provided. Form would could be lowered and not given as much attention for the viewer to appreciate the content of the piece. This balance is illustrated below.
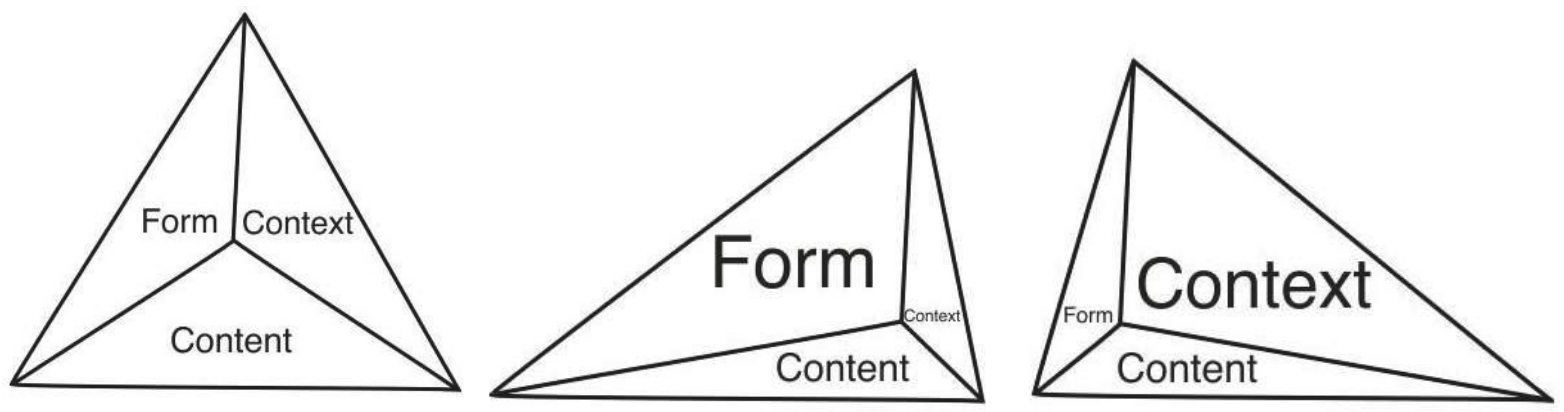


\section{The Creating Process}

"Painting is easy when you don't know how, but very difficult when you do."

\section{-Edgar Degas-}

My process of creating the artwork for this show was pulling from previous artists, ideas, styles, mediums, and bring forward to this new thing that I'm doing. I was rediscovering myself as an artist. I was making a statement to those who wanted to hear it. I went through the process of creating new techniques, some that worked, some that didn't. I yelled, and screamed. I found ways of understanding what it is to be what I wanted to say. I created art.

\section{Artist Statement}

Shannen Muhl is an interdisciplinary artist based in Portland Oregon. Shannen strives to find a balance between composition and emotive intuition in his work. While he tends to strongly use his history of depression and anxiety as source content, Shannen also has a strong interest in formalism, exploring technical methods, theories of color, composition, and mediums. He works to utilize the power and aesthetics of form, color, and at times sound to influence a psychological contemplation from the viewer.

\section{Show Quote}

This project is a culmination of my practice throughout the years. As an interdisciplinary artist, I have a very expanded skill set. I wanted to use this skill set to create and mold each form to fit inside an idea I Wanted to get across. This idea became my show quote and I brought form to it. 
"I'm attempting to create a conversation about the mannerisms and anxieties that are caused from living in a cityscape. We cram ourselves into smaller and smaller spaces, and expose ourselves to a variety of chaoses to live in this environment. I have a love hate relationship with this, and I strive to keep it constant."

I wanted to further expose the viewer to the bessarness of this thing we humans do. We want to live in a city for its beauty and culture, but a part of this is being exposed to the constant quick thumping of the cities heart. Outside my window a man screams, rolling in the street, the next apartment over has a single bedroom with four people living in it. We humans a putting ourselves into captivity. We are shoving ourselves into an extruder and injecting as much of ourselves into each crevasse of the city as we can. The city bursts at the seams with flesh and more come to do the same.

\section{Formal Creation Process}

Painting:

"I don't paint dreams or nightmares, I paint my own reality."

\section{-Frida Kahlo-}

I named this piece Apartmentalizing. I wanted to bring attention to the compartmentalizing we humans do when we cram ourselves into small city apartments (hence the name). I wanted people to ask why we do this to ourselves. These spaces act as little dark boxes we hide away in, which can deeply exacerbate the growing anxieties of city dwelling.

Being that the larger sum of my experience in the arts is painting I need less experimentation of material than I did with the other pieces I had created. I had decided to use oil paint for its diversity, on masonite for its availability, and ability to be constructional during mounting. I have deep interest and knowledge of 
application of the paint which I had gained during my previous researches into artists like Lucian Freud, and Kehende Wiley, whose works are focused on creating flesh. My exploratory focus was more towards properly relying the context, and giving the sense of being squished in a box. I had experimented with different images and collected source material from daily living and from other artists. Wangechi Mutu was a particular artist that interested me during creating this piece. Her ability to use nondescript sections of flesh in her collages to imitated other body parts was a technique which I had applied. I wanted the viewer to not be completely certain of some of the parts of the body that they were observing. Instead of collaging photos from magazines like Mutu, I found my sources elsewhere. I took pictures of leather couches because where two pieces intersected had the fleshy smooshed tension I was looking for. Also I took pictures of sections of my own body like my tightly closed armpit, close up on my closed fist, etc. also gave the effect I was looking for. The images I had created and formulated from this particular idea were vague enough to create curiosity but I felt still lacked the ability to fully bring the layman into the conversation. There wasn't enough balance of form and context. This is why I painted five pieces incorporating facial features, one with a foot, and one with a butt. These features are very recognizable by the mass public, which causes easier relation to the piece. Now both the artfully educated and the layman can converse on a common ground.

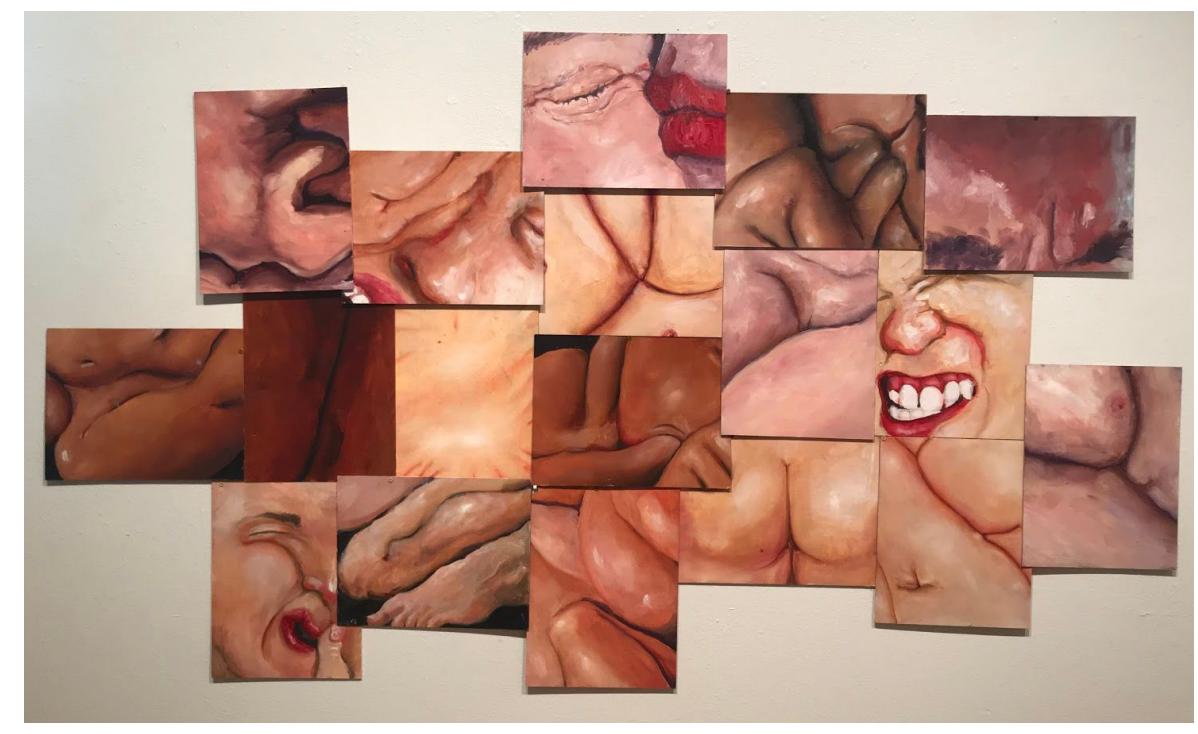

(Apartmentalizing, $1812 \times 16$ oil paintings on masonite) 
Video:

"My cow is not pretty, but it is pretty to me."

\section{-David Lynch-}

This video is where I wanted the feeling of anxiety to exist. Quickly moving eyes wandering all around and a mouth rapidly yelling something, but there is no sound. It's a screaming crack addict in the middle of the night, it's the angry driver stuck in traffic, it's manic mannerisms.

I used my interests in the camera shots used by the directors Sam Raimi and David Lynch. They're similar use of close in shots to immerse the viewer in scenes portraying tension, and anxiety. Using this I made footage of myself prying my eyes open looking around quickly and my mouth chomping and sped it up 40x to add to the feelings of manic and anxious mannerisms. The colors were made overly saturated to over stimulate the viewer.

This was projected on a loop above Apartmentalizing to enhance to feeling of weight. The title Cast Iron Roof is a contextual indication of this.With the manic anxious world outside the calmness is in the compressed. Discussions on weather or not I should allow a moment of calm in the crazed and quick loop but I feel that it gave Apartmentalizing the sense of calm within the boxes which one would feel in their apartment box. The piece below was the calm and the video projected remained the constant manic. 


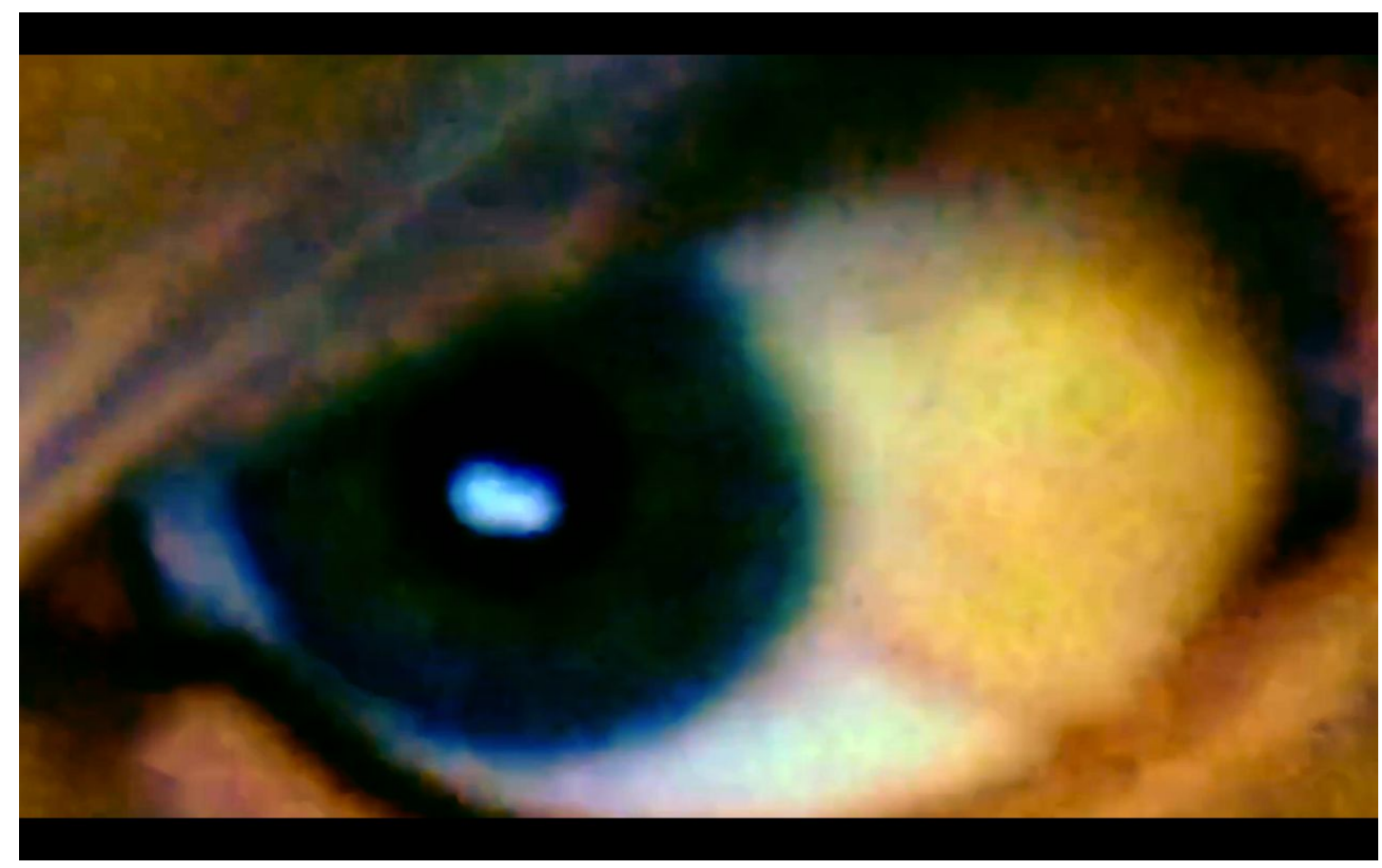

(Still from Cast Iron Roof, 5 hour and 10 minute looped video projected)

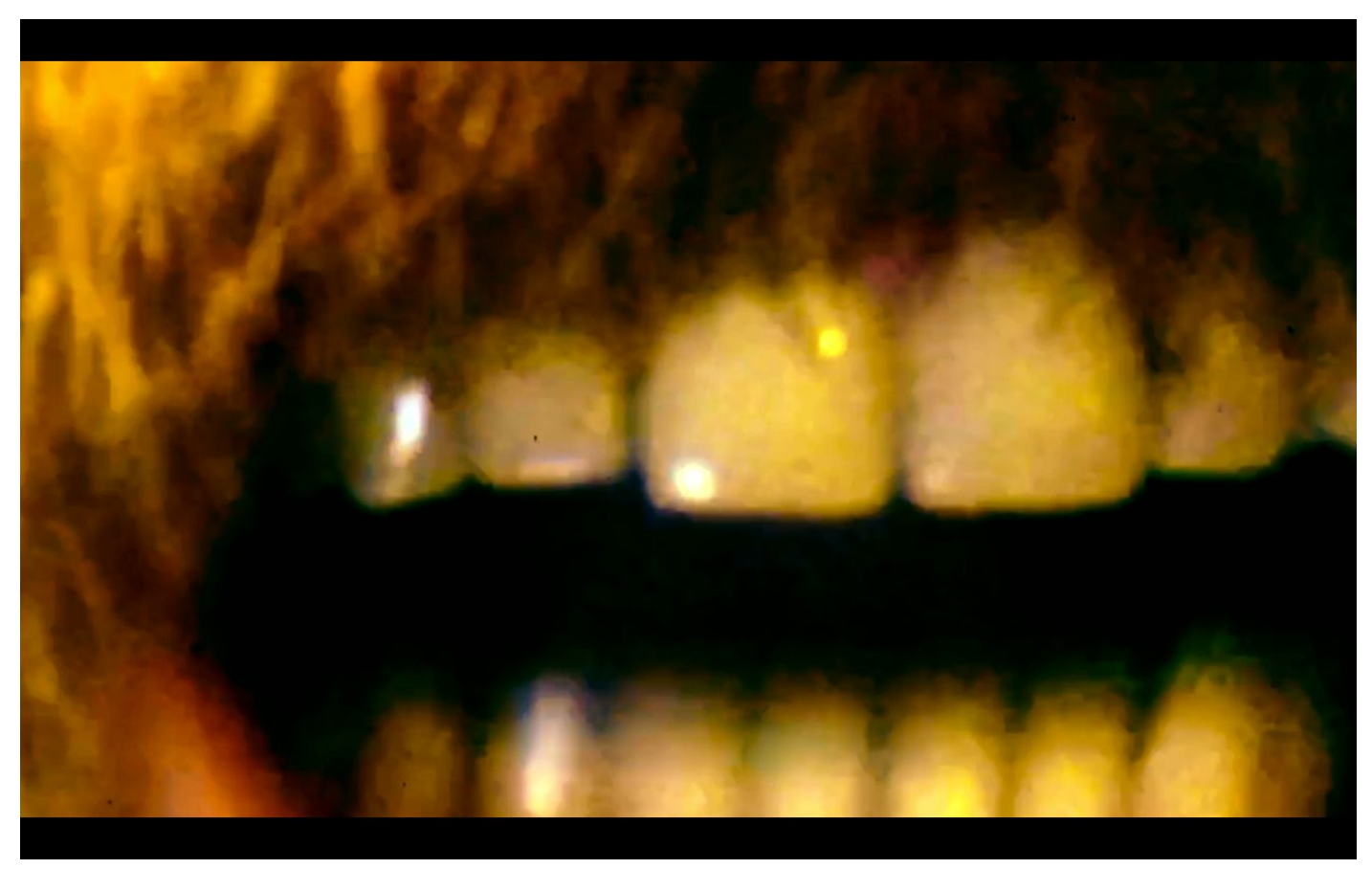

(Still from Cast Iron Roof, 5 hour and 10 minute looped video projected) 
Mounted Sculptures:

"I saw the angel in the marble and carved until I set it free"

\section{-Michelangelo-}

There were two mounted sculptures (as I called them). They were to represent the tension and overflow that happens when too many people cram into a small little space. One is humans spewing from the wall, like a infected disease, like a cancer, entitled Flesh Phlegm. The other is a focus on the individual, massive tension in being applied to this enormous hunk of flesh, but it still protrudes out like a belly with a belt tightened too much entitled Overhang. These two particular pieces were a sort of representation of the resentment I have for humans at times. I love people, but they are also at fault. They are the beauty and cancer in a cityscape. (Of course using they statements is a reflection on the mental isolation that can can happen in creating art. It is of course we because I too am included in the fault).

The two sculptural mounted pieces were where material experimental study on material was a major factor in their creation. I had a minor understanding in using expanding foam and plaster and their reactions to each other as well as paint. In the process so many different ways to manipulate these materials had to be researched, I poured plaster into balloons, and bowls, injected expanding foam into condoms, and into cracks, painted on each material at different levels of dryness. I observed the painting style of Tip Toland in her ceramic art sculptures, and attempted to emulate it. Eventually I had to just make up my own processes.

I started with Overhang. It seemed to be the less messy, and more straight forward process of the two. First I cut and created a $25.5 \times 25.5$ wooden frame. Next a large piece of a thick plastic bag was stapled around the edges and a thread of fishing twine across and over the plastic, not too taught as to allow a drooping or sagging. Then I flipped the frame over onto the edges of four chairs to allow the plastic to droop down freely. Once in place I mixed a large batch of plaster of paris until the consistency was smooth and poured it into the concave hanging plastic, 
pushing it up the edges to attempt a level thickness. I went through this process multiple times until I felt the thickness was good enough to be stable when dry (about an inch and a half throughout). Letting the piece dry was the more tedious part. It took nearly a week for the liquid to dissipate, which was important for maximum paint absorption. Once dry I flipped the sculpture on its back slid off the frame removed the plastic and twine, and underneath was the perfect looking piece of tense smooth unpainted flesh. I painted it using washes of acrylic paints first cadmium orange, then raw sienna with titanium white, some burnt sienna, flicks of burnt umber for freckles, a touch of ultramarine blue for veins and then presto. The paint was sealed using acrylic top coat spray and all that needed to be done was to secure the frame on top. I used glue and expanding foam for this part (though in retrospect, it would have been easier to use caulking). Next I used a concrete patching putty to coat the frame to give it a more industrial look. Once it was all dry it looked perfect.

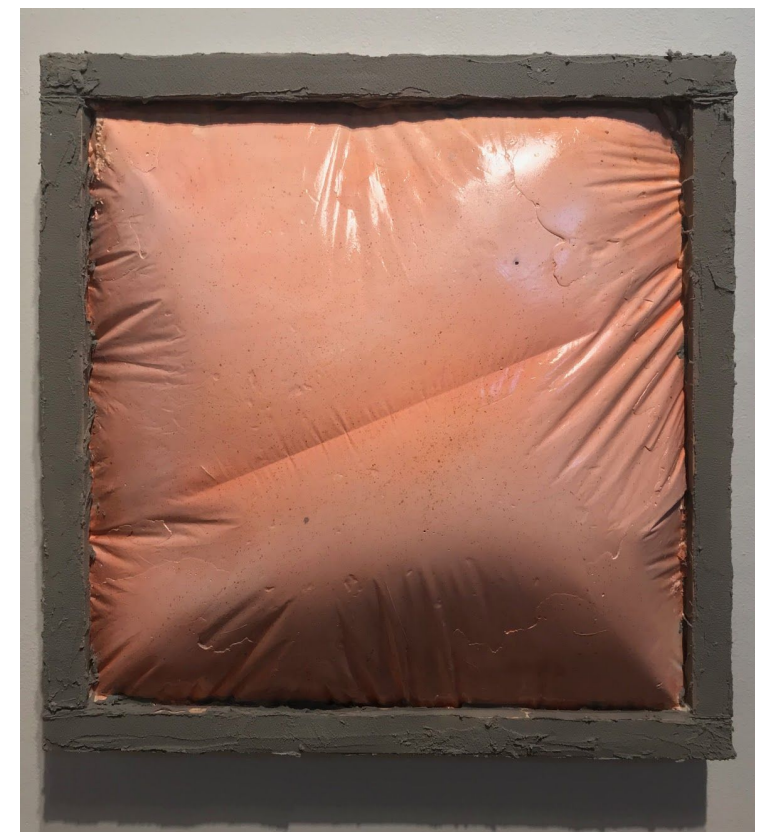

(Overhang,25.5x25.5, mixed media)

For Flesh Phlegm I want on a slightly different route though with the same start. Like Overhang I started with a $25.5 \times 25.5$ frame, but this time I simply laid it into a plastic sheet. Then I went through the process of injecting areas with 
expanding foam, waiting about 15 minutes for it to dry and then injecting more, until the entire frame was filled with lumpy, bulbous shapes. Next I mixed plaster of paris and poured a thick layer on top and waited until it was slightly thicker. At this point was where I was able to create the oozing dripping effect by tilting the piece up 45 degrees and giving it a good knock on the table, not too hard but just enough to give it a sense of gravity. I let the plaster dry for about a week and then painted it in the same way as I did with Overhang except this time I wanted to give the illusion that this piece was made of many different people all with different skin tones. Each section individually had its own set of colors to create it flesh tones. Some had more raw umber, some more raw sienna, others had more freckles or a mole. Once finished I painted a blue and red vein throughout the entire piece to suggest the idea that even though this is created out of many people it's all one single organism. After mounting it on the gallery wall, I used more expanding foam around the edges of the outside of the frame and the painted it the same white as the wall. This was to give the illusion of being exposed and oozing out from the wall.

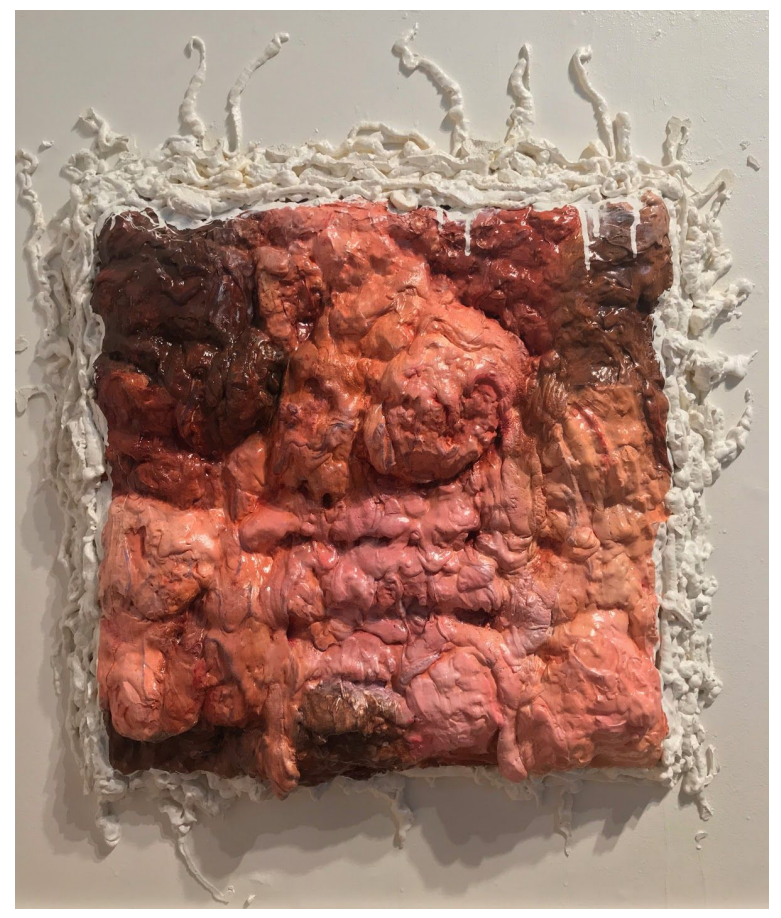

(Flesh Phlegm, 25.5×25.5 mixed media) 
Performance:

"I became an artist because I wanted to be an active participant in the conversation about art." -Kamand Kojouri-

This is how I created a live visual tension. Watching someone struggle can cause an empathetic outburst, making the viewer experience uncomfortable sensations, called cringe. This cringe Makes the viewer not want to watch, of help with the situation. I wanted this performance piece to be different personal tensions we put ourselves in. Struggles that we begin and have difficulties going through. Stress Compulsion was not only the name of the show but it was the name of this.

Throughout the art show every hour on the half hour I slug myself into a silk harness which was attached to the corner of where the ceiling met the wall. Once I was in the harness I hung with my feet on the brick wall and the floor below me over a Piece of paper barely in reach. The performance was the action of me struggling to create a finished piece of art. During the duration certain "mishaps" would happen that I purposely caused, like my calls rolling just out of reach, of spilling the water I dunk them into. There were time in which people attempted to help me but I had others in the crowd telling them not to.

There were three separate performances each was an attempt at drawing a different life's struggle. The first being a diploma cap and gown. This is to iterate the difficulties of graduating college (being that I was nearly doing so myself). The second was an image was of a cityscape, bring the other pieces in the art show into context of the performance. The last was a rough sketch image of myself smiling. This particular one was more of an easier broad more relatable message, the struggles of being happy. It's hard to maintain happiness and it's a struggle to find ways of doing so in life. 


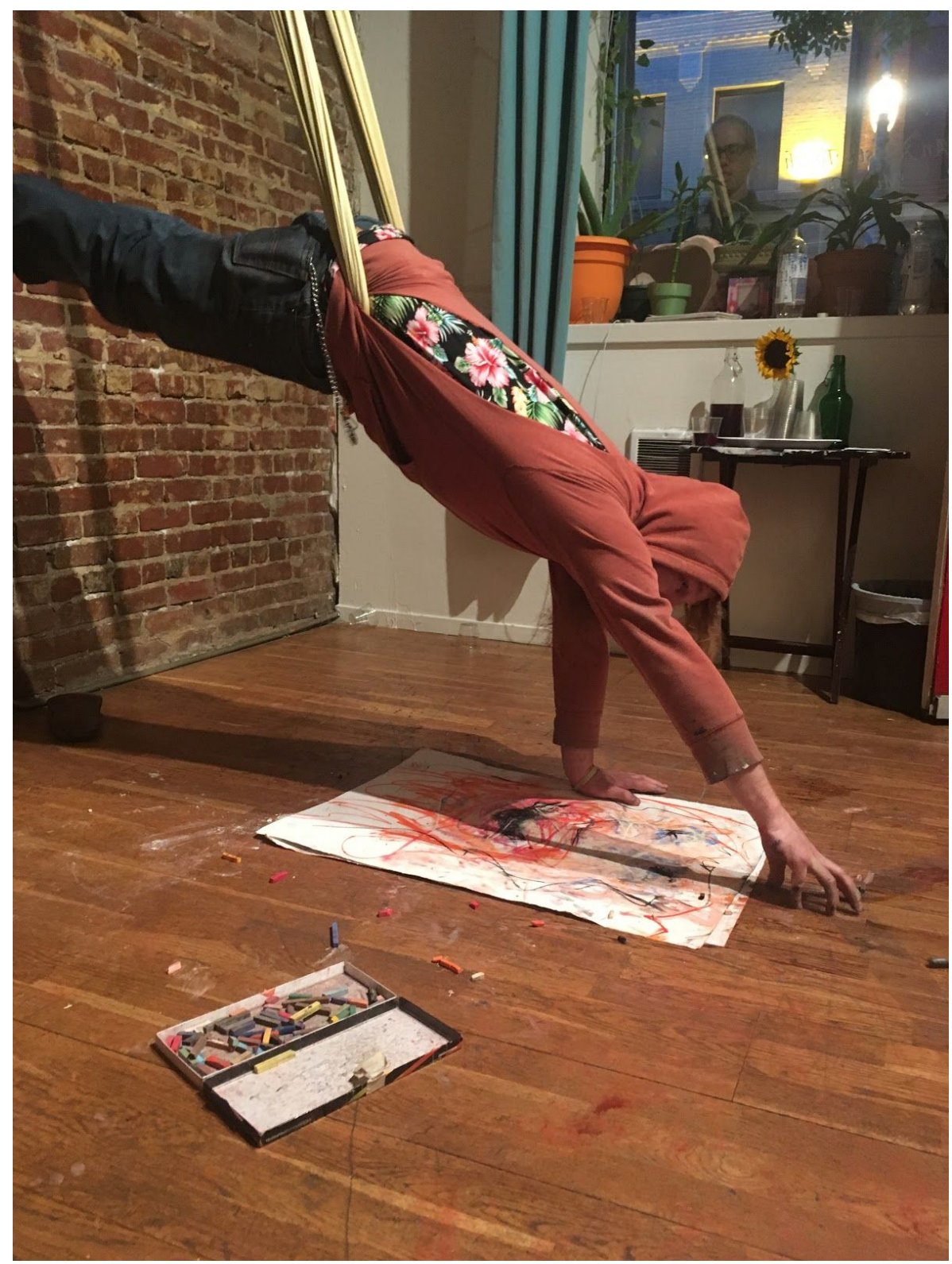

(Stress Compulsion, 30 min. performance) 
Past Work:

"If you hear a voice within you say you cannot paint, then by all means paint and that voice will be silenced."

\section{-Vincent van Gogh-}

The last piece being discussed is Humans in a Confined Space. This was the first painting I had done with this particular context in mind. I painted it three years ago after going through some time of artistic mental blockage. I had moved back to Portland Oregon after experiencing an extreme trama leaving me with what was diagnosed as PTSD. I had bouts of anxiety attacks, anger, and strange mannerisms were spewing from my psyche. These were exacerbated by being in a city environment, but it also caused a hyper awareness of others with similarities. I found a fond interest in this and longed to find a way of expressing it. During this same time I was researching painters like Rick Bartow and Francis Bacon, which bacme incredible influences on me. They had a way of expressing anguish, pain, and angst by combining beauty and grotesque, so I started to do the same.

I started to use the canvas as a box in which to place the subject. This was their confinement, their glass box I shoved the into, to allow their mannerisms to immerge. I began with Cowering (left panel) Cowering from the busy outside was the first one. I cut into the perfect white canvas with my dark charcoal, violating its perfection. I used it like a knife to cut away the outline of this cowering person hiding behind white cloth. Each mark a sign of confidence of where it belonged. "This mark is a foot, this is their face, and this is also their face, as well as this." Next was the paint. This moldable textural goop. I spread it around this person, pulling them further out of the canvas, and pushing back what was behind them. Slowly the image was born. Born cowering from the world exposed to them.

The next panel was Chronicly Materbating (righ panel). The process was the same but the mannerism was different. Why chronicly masterbating? It is the symbol of desperately seeking positive stimulus in a world so void of it. The manic, mind needs this to continue, but of course is ashamed after. The same arm that 
grabs their chest in a moment of excitement is the same arm that cradles their face in shame. This action of chronicly masterbating is liken to that of the heroin junky, the crack addict, the compulsive eater, the drinker, etc.

The middle panel Weight was created in an attempt at giving a sense of weight and placement. I had created vague abstracted concrete structure with ghostly orange figures places within them. This is where they are. This is how much thick concrete material is between them and the next person. Each in their own concrete boxes, each struggling to find a moment of sanity or clarity.

I added this piece in an attempt at show the history of the context I'm giving. I'm not simple grabbing ideas from thin air, this has been a long thought out process, of evolution, growth, and refinement.

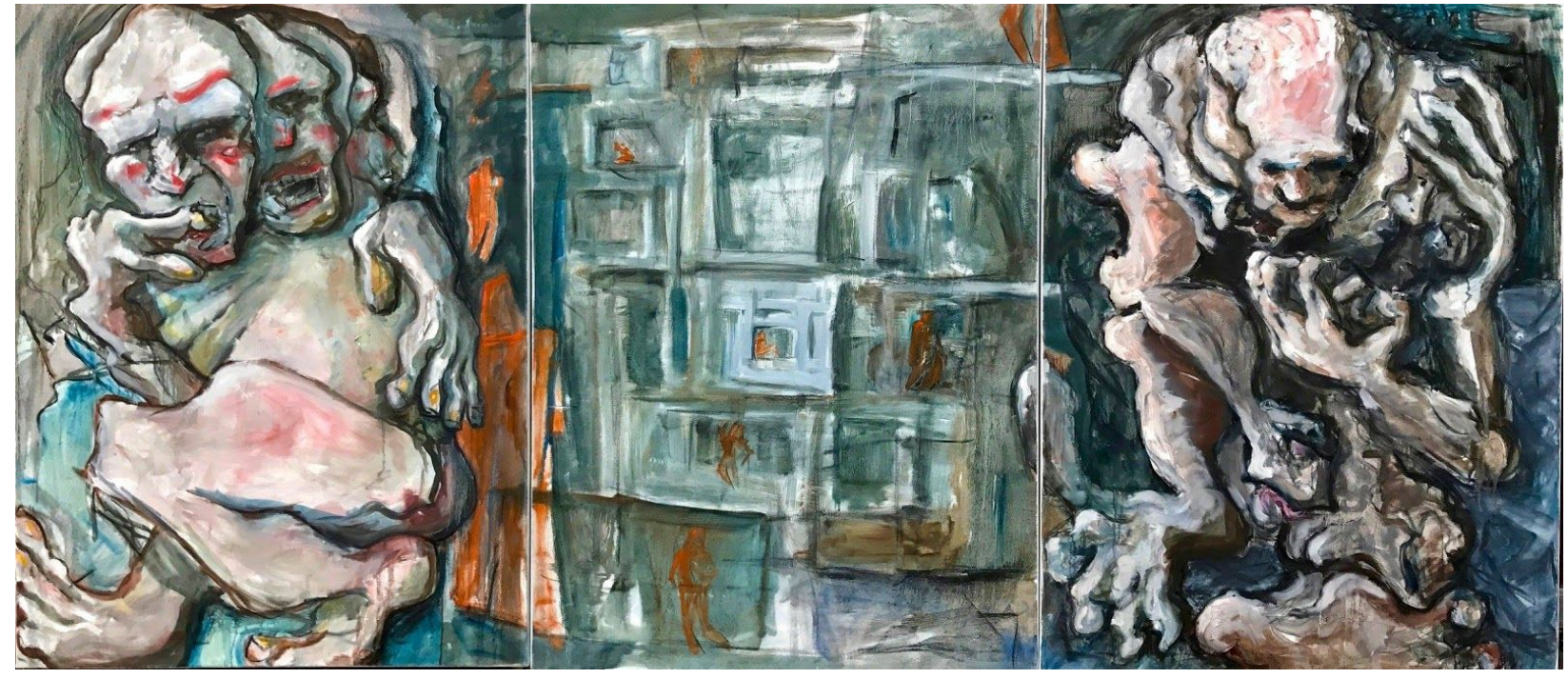

(Humans in a Confined Space, oil on $330 \times 40$ canvas) 


\section{The Gallery}

"The nice thing about the gallery shows is that without having to pay any money you can just go and see it" -Yoko Ono-

To curate a show the first thing that one must do is understand the space in which the show will be held. I had to measure every walls width and length, create a map to understand my options. The created map is shown in the following image.

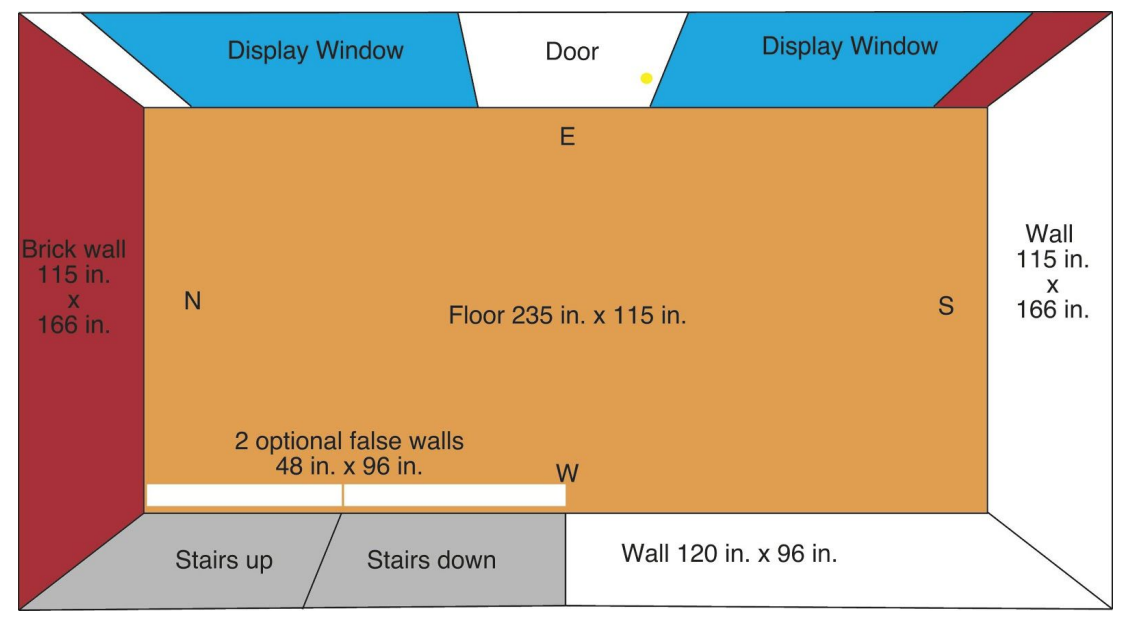

(Gallery Map)

I had potentially five surfaces on which to hang the mountable pieces. One large white drywall surface measuring $115 \mathrm{~W} \times 166 \mathrm{~L}$ inches, one medium white drywall surface measuring $120 \mathrm{~W} \times 96 \mathrm{~L}$ inches, one red brick wall surface measuring $115 \mathrm{~W}$ $\times 166 \mathrm{~L}$ inches, and two spare drywall false wall surfaces bothe measuring $48 \mathrm{~W} \times 96$ $L$ inches to potentially use as a way of blocking a large opening measuring 96 inches across.

Now having the gallery map I now have the means to have a better idea where each piece will go. 


\section{Hanging Techniques}

Two main points to keep in mind are allowing the viewer to experience each piece separately and allowing the viewer to experience everything as a whole. To do this I selected the appropriate wall to hang each piece with it appropriate spacing.

There are many ways to hang mountable art. Finding the particular sweet spot to hang a piece on a wall in relation to other pieces, walls, windows, doors, and general walking flow is no easy task. One could use the tradition of hanging salon style, which is to cram as much on to a single wall as possible. The gallery standard, which has specific measurements to take, or one could go a more personalized contemporary way. I chose to hang most of my work keeping standard gallery measurements, but adding a little of my own twist on some.

\section{Standard Hanging}

The standard height for most galleries and museums is to keep the center at 60 inches (which of is the height average person's view). To do this you first must measure the height of the painting, lets say that it's 36 inches. Divide it in half to find its center points which is 18 inches. Keep track of this number. On the back of the painting there will either be hanging wire, D rings, just stretcher bars, or nothing at all. If it's hanging wire measure the length from the hanging point to the top. If there are D rings measure both the hanging point to the top and the width between each $D$ ring. If there are stretcher bars measure the bottom of the top bar to the top. If there is nothing, then measure nothing. For this let's take the wire example. Usually the length is 1 inch or so. Now for the math, take the half height of the painting 36 , add it to the average viewpoint 60 , and subtract the hanging point $1.36+60+1=95$. Now we have the height to hang the painting.

The width spacing is a bit easier to calculate. Take the total width of all the pieces being hung on one wall let's say it's 3 paintings. One is 24 inches one is 36 
inches, and one is 8 inches, $24+36+8=68$. Keep track of this number. Take the number of spaces between each painting 4. Keep track of this number. Subtract the total width of the paintings from the width of the wall, let's say the wall is 155 inches across. $155-68=87$ inches. Now divide the spaces between paintings $87 / 4=$ 21.75 inches. Now we have the spacing of each painting on the wall.

Now we take the height and lightly mark it on the wall with pencil, measure the first width from the corner and mark it. Add half the width of the first painting $24 / 2=12$ and find the intersection of the height and width. This is our center hanging point which should measure 95 inches up and 33.75 inches from the corner. Use a level measure one inch on each side of of the hanging point. This is the drill point. Drill a drywall screw into each screw poin leaving about half an inch exposed.

Gently lift the painting and lay the wire across the two screws. Adjust until the sides of the painting lie between the first marked width from the corner. Place a level on top of the painting and adjust until level. The fist painting is now in place. Repeat these steps for the rest of the paintings using the previous painting as reference.

I used this style to hang three of my pieces on the Western wall and the false wall. Note that I decided to use only one false wall and then suspend it from the ceiling on its side at the 60 inch center mark and in between the open space.

\section{Personalized Hanging}

For my particular show, I wanted to add a bit of my own personalized mean of hanging. Being interdisciplinary in my art, I wanted to show my work in more of an interdisciplinary manner.

After hanging two of my three of my pieces in the way of gallery standard, I decided to take a different route with eighteen others. To get across the shows idea of a cramped space, I thought that hanging my smaller paintings in a clustered 
slightly stacked way would give the viewer more of that kind of feel. So I measured the center point of the South wall and hung my paintings, expanding from that spot. It gave the smaller paintings an identity of a whole single piece, and gave somewhat of the effect I was looking for. To further add to the crampedness I projected my video piece a foot above it, adding weight to the paintings below.

\section{The Checklist}

Now that all of the paintings were up I needed to create the gallery checklist. This is a way to avoid having label plaques next to the paintings which I feel tends to distract too much from the pieces. It's also a nice way for the viewer to read my artist statement, my show quote, and have a list of the paintings. Which is show in the following two images. 


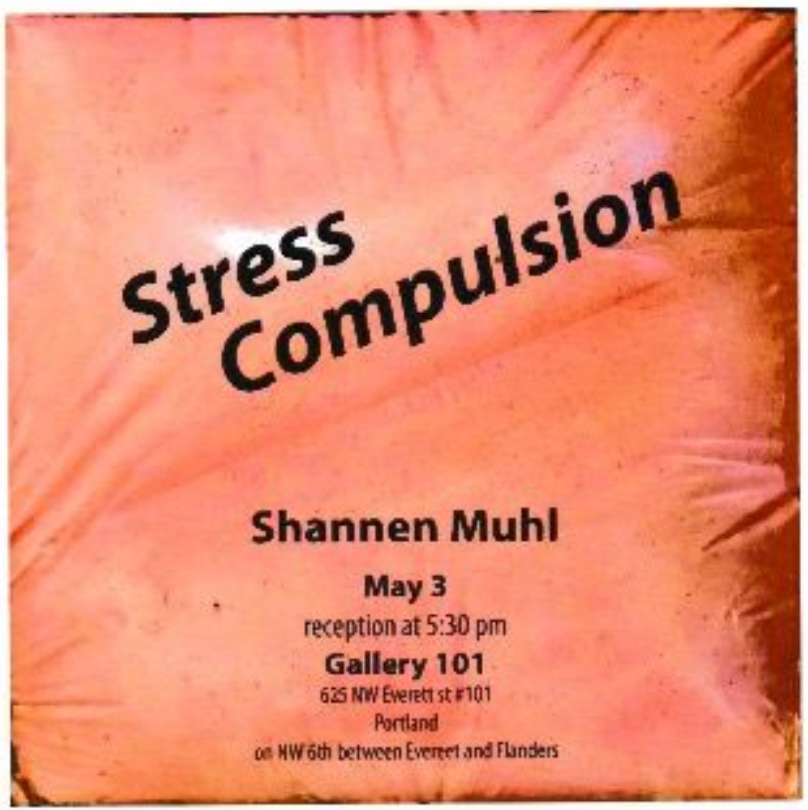

Shannen Muhl is an Interdisciplinary artist based in Portland Oregon. He strives to find a balance between composition and emotive intuition in his work. While he tends to strongly use his history of depression and anxiety as source content, Shannen also has a strong interest in formalism, exploring technical methods, theories of color, composition, and mediums. $\mathrm{He}$ works to utilize the power and aesthetics of form, color, and at times sound to influence a psychological contemplation from the viewer.

"I am attempting to create a conversation about the mannerisms and anxieties that are caused from living in a cityscape. We cram ourselves into smaller and smaller spaces, and expose ourselves to a variety of chaos to live in this environment. I have a love hate relationship with it, and I strive to keep it constant." 


\section{Check list}

As you enter start left wal continuel clockwise

1. Video: Cast Iron Roof

2. Apartmentalizing

3. Flesh Phlegm

4. Overhang

5. Humans in a Confined Space

6. Performance: Stress Compulsion 


\section{The Show}

"The show must go on"

\section{-P.I. Barnum-}

After all the creating and curating all that was left to do was to open the doors talk to visitors, and preform. This in itself should be considered an art form. The art of schmoozing and giving each person the appropriate amount of time to talk about the art. Each person had their own questions, ideas, comments, and critiques, which were all welcome. I had received amazing feedback about each piece, from those who I respect and admire. Even the performance, which I wasn't exactly sure how well it would be digested, was a big hit. All the work, all the research, all for this. It was an amazing experience that I hope to do again and again.

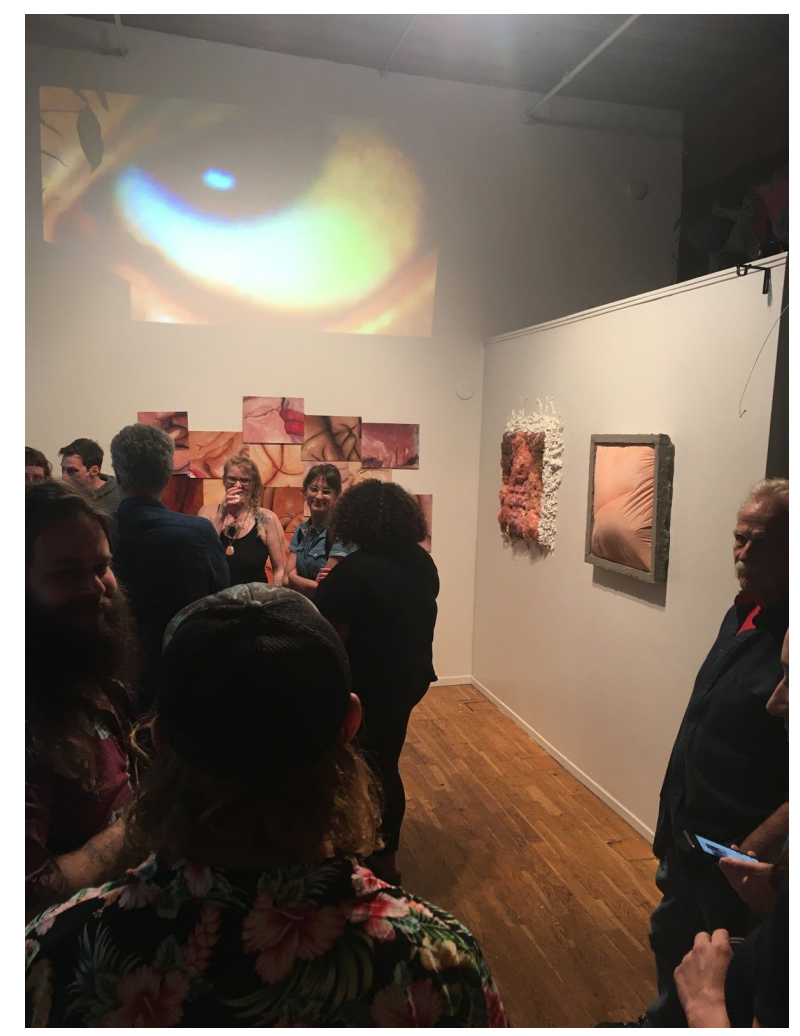

(a picture taken during the art show) 
Thank you

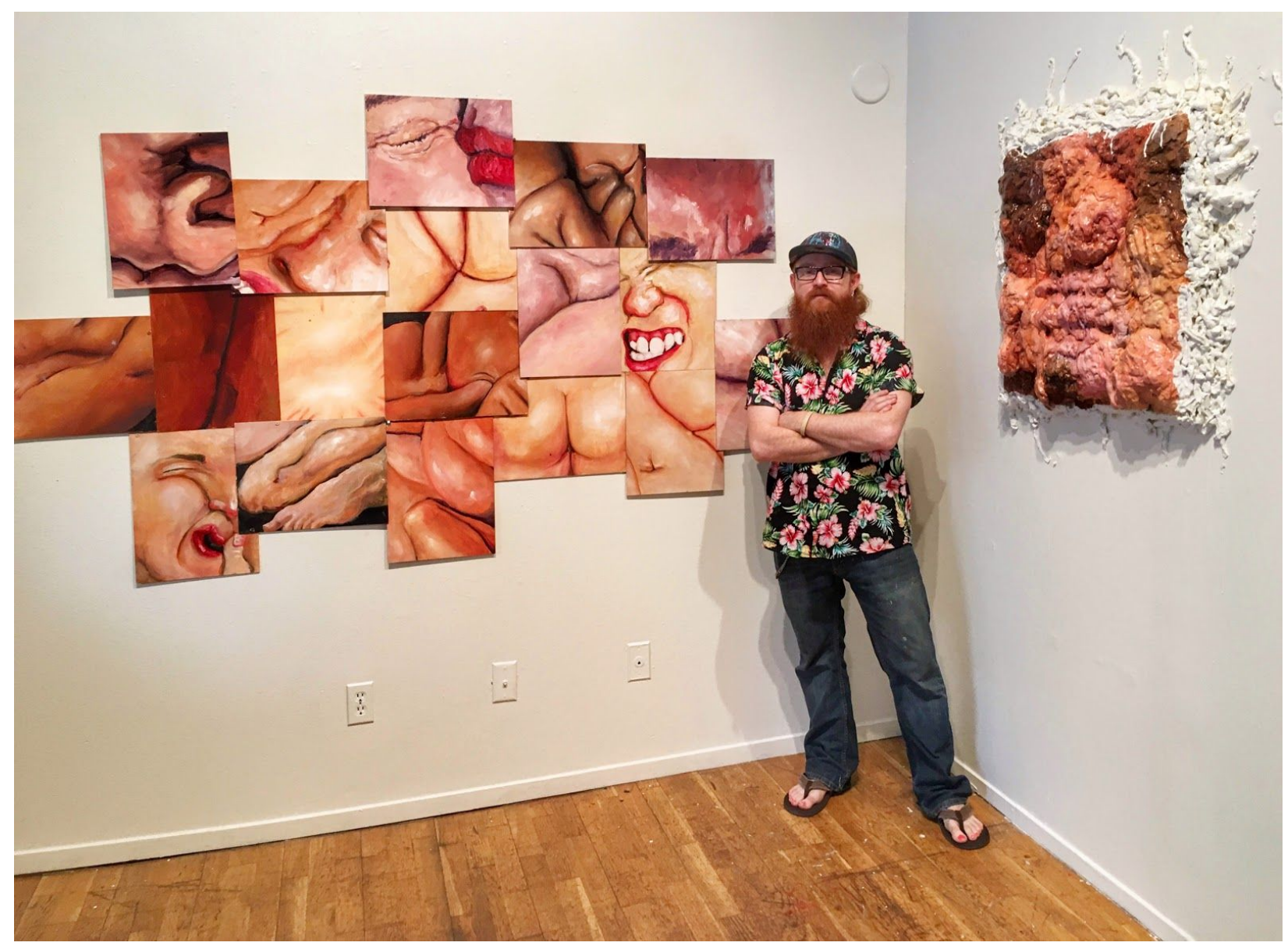

-Shannen Muhl-

shannenmuhl.com 